\title{
Frequency and Genotype of Human Parvovirus B19 among Iranian Hemodialysis and Peritoneal Dialysis Patients
}

\author{
Alireza Sharifa ${ }^{a}$ Arezoo Aghakhani ${ }^{d}$ Ali Akbar Velayatif ${ }^{f}$ Mohammad Banifazlg \\ Mohammad Reza Sharif ${ }^{b}$ Effat Razeghi ${ }^{h}$ Davood Kheirkhah ${ }^{c}$ \\ Monireh Kazemimanesh $^{\text {e }}$ Anahita Bavand ${ }^{d}$ Amitis Ramezani $^{d}$ \\ anfectious Diseases Research Center, ${ }^{b}$ Autoimmune Diseases Research Center and ${ }^{\mathrm{c}}$ Department of Pediatrics, \\ Kashan University of Medical Sciences, Kashan, ${ }^{d}$ Clinical Research Department and 'Virology Department, \\ Pasteur Institute of Iran, ${ }^{f}$ Pediatric Respiratory Diseases Research Center, Shahid Beheshti University of Medical \\ Sciences, 9 Iranian Society for Support of Patients with Infectious Disease, and hephrology Research Center, \\ Tehran University of Medical Sciences, Center of Excellence in Nephrology, Tehran, Iran
}

\section{Keywords}

Hemodialysis patients · Peritoneal dialysis patients · Human parvovirus B19 · Serology · Genotype · Anemia

\footnotetext{
Abstract

Objectives: The aim of this study was to evaluate the frequency and genotype of human parvovirus B19 and its relation with anemia among Iranian patients under dialysis. Methods: Fifty hemodialysis (HD) and 33 peritoneal dialysis (PD) patients were enrolled. B19 IgG and IgM antibodies were assessed by ELISA, and the presence of B19 DNA was evaluated by nested PCR. PCR products were sequenced directly and phylogenetic analysis was performed. Results: In the HD group, the prevalence of B19 antibodies was 54\% for IgG and 4\% for IgM. B19 DNA was detected in 10\% of the cases, and $10 \%$ showed B19 lgG and viremia simultaneously. In the PD group, the prevalence of B19 IgG and IgM was 57.6 and $0 \%$ respectively, whereas B19 DNA was found in $12.1 \%$ of the group. A total of $9.1 \%$ showed B19 lgG and viremia
}

concurrently. There was no significant difference regarding anemia and B19 infection in either group. All B19 isolates were clustered in genotype $1 \mathrm{~A}$. Conclusion: Our findings indicate that B19 infection plays no role in leading chronic anemia in dialysis patients. However, persistent B19 viremia and the circulation of the same strains in dialysis patients may indicate a potential risk for the contamination of dialysis equipment and nosocomial spread of B19 infection within dialysis units.

๑) 2017 S. Karger AG, Basel

\section{Introduction}

Parvovirus B19 (B19) is a small nonenveloped singlestranded DNA virus belonging to the Parvoviridae family and Parvovirinae subfamily [1]. Respiratory spread appears to be the most common route of B19 transmission and the virus is easily transmitted with close contact but can also be acquired through blood and blood prod-

\section{KARGER}

E-Mail karger@karger.com

www.karger.com/int
(C) 2017 S. Karger AG, Basel

0300-5526/17/0593-0179\$39.50/0
Amitis Ramezani

Clinical Research Department, Pasteur Institute of Iran

13164 Pasteur Avenue

Tehran (Iran)

E-Mail amitisramezani@hotmail.com 
ucts. The vertical route of transmission from mother to fetus and nosocomial transmission of the virus have also been documented $[2,3]$.

In immunocompetent subjects, acute B19 infection is usually mild and associated with transient anemia, arthritis, and rash. It was shown that after acute B19 infection, B19 DNA remains in bone marrow, kidney, liver, myocardium, and other organs [4-6]. In contrast, in immunosuppressed cases, acute B19 infection may be associated with severe symptoms. Generally, solid organs or stem cell recipients are at increased risk for viral reactivation that may originate from a persisting previous viral infection or from transmitted pathogens through the transplantation [7]. Due to notable tropism of B19 to human bone marrow and erythroid precursor cells for replication, anemia is considered the main complication of B19 infection [8]. B19 infection can also cause aplastic crisis in patients with chronic hemolytic anemia.

Patients with renal failure on dialysis have disruptions in their immune system due to the immunosuppressive effects of uremia, deficient erythropoietin production, and significantly decreased erythrocyte survival $[9,10]$. Therefore, dialysis patients reveal increased susceptibility to acute and chronic anemia after B19 infection. Moreover, B19 infection can induce aplastic crisis in dialysis patients similar to hemolytic anemia cases [11]. On the other hand, some authors believe that erythropoietin administration during B19 infection can facilitate viral replication [12]. Nosocomial spread of infection in the dialysis unit is also a potential threat, although this is not well explained in the literature [3]. Finally, persistent B19 infection in patients on chronic dialysis could be clinically symptomatic after renal transplantation and the consumption of immunosuppressants [13]. Therefore, it seems that B19 infection in dialysis patients can be noticeable. Nowadays, persistent B19 infection has a special significance and is of great interest in different settings, including dialysis patients [14-18].

Three distinct genotypes of B19 have been described: genotype 1 , with subtypes $1 \mathrm{~A}$ and $1 \mathrm{~B}$, genotype 2 , and genotype 3, with subtypes $3 \mathrm{~A}$ and $3 \mathrm{~B}[19,20]$. Available data show some geographical restrictions for B19 genotypes. Genotype 1 is the most common B19 genotype detected worldwide, while genotype 2 has been reported from western countries like Germany [21], Finland [22], the USA and Brazil [23,24]. Genotype 3 has been restricted to samples from French and Brazilian patients and Ghanaian blood donors [19, 24, 25].
However, there are insufficient data regarding the distribution and molecular epidemiology of B19 in dialysis patients, while this population may be vulnerable to anemia due to B19 infection. We therefore aimed to evaluate the frequency of B19 in Iranian hemodialysis (HD) and peritoneal dialysis (PD) patients, and to explore their molecular characterization as well as its relation to anemia.

\section{Patients and Methods}

\section{Study Population}

In this cross-sectional study, 83 dialyzed patients (50 on HD and 33 on PD) who were referred to the main dialysis units of Tehran, Iran, were consecutively enrolled in the study from September 2014 to November 2014. A questionnaire was provided to collect epidemiological and clinical data such as age, gender, length of time on dialysis, and previous medical history. The study protocol was approved by the ethical committee of the Iranian Society for Support of Patients with Infectious Diseases and informed consent was obtained from all patients. Anemia in dialysis patients has been defined by the World Health Organization [26] as a hemoglobin concentration $<13.0 \mathrm{~g} / \mathrm{dL}$ for adult males and postmenopausal women, and $<12.0 \mathrm{~g} / \mathrm{dL}$ for premenopausal women.

\section{Serological Assessment}

All plasma samples were tested for B19 virus-specific antibodies using enzyme-linked immunosorbent assay (ELISA) kits for the detection of B19 IgG and IgM antibodies (EUROIMMUN, Lübeck, Germany). These assays were performed according to the protocols provided by the manufacturer. The serum hepatitis $B$ surface antigen (HBsAg), hepatitis B core antibody (anti-HBc), and hepatitis $\mathrm{C}$ antibody (anti-HCV) levels were also detected by ELISA. The commercial enzyme immunoassay kits used were from Dia.Pro Diagnostic BioProbes (Milan, Italy). Human immunodeficiency virus (HIV) infection was diagnosed by ELISA (MP Biomedicals, Illkirch, France) with confirmatory Western blot analysis (Diaplus, San Francisco, CA, USA).

\section{DNA Extraction and PCR}

B19-DNA was extracted from $200 \mu \mathrm{L}$ of plasma using the RTP DNA/RNA Virus Mini Kit (Invitek, Berlin, Germany) according to manufacturer's instructions. The extracted DNA was stored at $-20^{\circ} \mathrm{C}$ before PCR analysis.

In order to evaluate the suitability of extracted DNA, $\beta$-globin gene amplification was performed using PCO3 ( $5^{\prime}$-ACACAACTGTGTTCACTAGC- $3^{\prime}$ ) and PCO4 (5'-CAACTTCATCCACGTTCACC- $3^{\prime}$ ) primers which amplify a 110 -bp fragment. PCR was carried out in a $25-\mu \mathrm{L}$ amplification mixture containing $1 \mu \mathrm{L}$ of extracted DNA, $1.5 \mathrm{mM}$ of $\mathrm{MgCl}_{2}, 15 \mathrm{mM}$ of Tris- $\mathrm{HCl}$ ( $\left.\mathrm{pH} 8.0\right), 0.2$ $\mathrm{mM}$ of dNTP, $50 \mathrm{mM}$ of $\mathrm{KCl}, 10 \mathrm{pmol}$ of each primer, and $1.5 \mathrm{U}$ of Taq polymerase (YTA PCR Master Mix). $\beta$-Globin-positive samples were subjected to nested PCR.

A fragment of the DNA sequence coding for the major capsid protein (VP2) of parvovirus B19 was amplified by nested PCR. The first round of PCR was carried out using the primer pair TJI 
Table 1. ELISA and PCR results in $\mathrm{HD}$ and PD patients

\begin{tabular}{llllll}
\hline Dialysis patients & $\begin{array}{l}\text { B19 IgM, } \\
n(\%)\end{array}$ & $\begin{array}{l}\text { B19 IgG, } \\
n(\%)\end{array}$ & $\begin{array}{l}\text { B19 DNA, } \\
n(\%)\end{array}$ & $\begin{array}{l}\text { B19 IgM + IgG, } \\
n(\%)\end{array}$ & $\begin{array}{l}\text { B19 IgG + B19 DNA, } \\
n(\%)\end{array}$ \\
\hline HD $(n=50)$ & $2(4)$ & $27(54)$ & $5(10)$ & $1(2)$ & $5(10)$ \\
PD $(n=33)$ & $0(0)$ & $19(57.6)$ & $4(12.1)$ & $0(0)$ & $3(9.1)$ \\
\hline
\end{tabular}

(5'-TTCTTTTCAGCTTTTAGG-3' [nucleotides 3775-3792]) and R4154 (5'-TATTCCTGTGACATATTT- ${ }^{\prime}$ [nucleotides 4171-4154]), which were described previously by Melon et al. [27]. The first round of PCR was performed with $10 \mu \mathrm{L}$ of DNA extract added to an amplification mixture containing $2.5 \mu \mathrm{L}$ of $10 \times$ PCR buffer, $1 \mu \mathrm{L}$ of $\mathrm{MgCl}_{2}, 0.75 \mu \mathrm{L}$ of dNTP mix, $0.4 \mu \mathrm{L}$ of Taq polymerase, $1 \mu \mathrm{L}$ of each primer in a total volume of $15 \mu \mathrm{L}$ ( $8.35 \mu \mathrm{L}$ of distilled water). The PCR profile was an initial $5 \mathrm{~min}$ denaturation at $94^{\circ} \mathrm{C}$, followed by 35 cycles of amplification, including denaturation for $30 \mathrm{~s}$ at $94^{\circ} \mathrm{C}$, annealing for $40 \mathrm{~s}$ at $45^{\circ} \mathrm{C}$, and extension for $50 \mathrm{~s}$ at $72^{\circ} \mathrm{C}$. Strand synthesis was completed at $72^{\circ} \mathrm{C}$ for $10 \mathrm{~min}$ and stored in $4^{\circ} \mathrm{C}$ for $5 \mathrm{~min}$. A total of $2 \mu \mathrm{L}$ of the first-round PCR products was then subjected for the second-round PCR under the same conditions but with the primers TJ2 (5' ${ }^{\prime}$ TATAAGTTTCCTCCAGTGCC-3' ${ }^{\prime}$ [nucleotides 3818 3837]) and TJII (5'-TGAATTGCATGGTCTTCATG- $3^{\prime}$ [nucleotides $3975-3956]$ ) in a total volume of $23 \mu \mathrm{L}$ of amplification mixture $(16.35 \mu \mathrm{L}$ of distilled water). The expected size of the second PCR product was $158 \mathrm{bp}$. Each batch included negative controls containing water and B19 plasmids as positive controls. The PCR products were electrophoresed on a $1.5 \%$ agarose gel with the 100-bp DNA ladder (SinaClon, Tehran, Iran), stained with ethidium bromide, and visualized by ultraviolet transillumination.

\section{DNA Sequencing, Genotyping and Phylogenetic Analysis}

Nested PCR products were purified using the QIAquick PCR purification kit (Qiagen, Hilden, Germany) and then sequenced directly for both directions at Pishgam Biotech Company (Tehran, Iran) using the Sanger method. The phylogenetic analysis was based on B19 VP2 sequences of the patients described in this study and reference sequences of various B19 subtypes downloaded from the GenBank database.

Nucleotide sequences were aligned using the CLUSTAL W program in CLC Main Workbench 6.5 software (CLC Bio, Qiagen). The genetic distance was calculated using the Kimura 2-parameter matrix. A phylogenetic tree was subsequently constructed by the neighbor-joining method and tested with the bootstrap resamplings (1,000 replicates) using the MEGA program, version 5 . The B19 sequences obtained in this study were deposited in the GenBank under accession No. KU891254-62.

\section{Statistical Analysis}

Statistical analyses were conducted using SPSS statistics software (version 16, Chicago, IL, USA). The $\chi^{2}$ test or Fisher exact test was used to compare variables. Data are presented as the mean \pm SD or, when indicated, as an absolute number and percentage. $p$ values $<0.05$ were considered statistically significant.

Parvovirus B19 in Dialysis Patients

\section{Results}

A total of 50 patients on $\mathrm{HD}$ (mean age $53.18 \pm 16.44$ years) and 33 patients on PD (mean age $53.66 \pm 13.02$ years) were enrolled in the study. The overall prevalence of B19-specific IgG in patients under dialysis was $55.4 \%$ (46 of 83) and of B19 IgM was 2.4\% (2 of 83). B19 DNA was detected in $10.8 \%$ (9 of 83 ) of cases. One sample was positive for both antibodies, while 8 cases (9.64\%) revealed B19 IgG and viremia concurrently. The mean $\mathrm{Hb}$ in $\mathrm{HD}$ and $\mathrm{PD}$ patients was $10.51 \pm 1.57$ and $11.23 \pm 2.1$ $\mathrm{g} / \mathrm{dL}$, respectively. Anemia was found in $86.74 \%$ of dialysis patients. Erythropoietin (EPO) was received by $60.2 \%$ cases. All $\mathrm{HD}$ patients were negative for $\mathrm{HBsAg}$, anti$\mathrm{HBc}$, and anti-HIV. One HD patient had anti-HCV.

In the $\mathrm{HD}$ group, $38 \%$ were male and $62 \%$ were female. The mean duration of dialysis was $56.58 \pm 52.46$ months and the dialysis interval was 3 times a week. The prevalence of B19-specific immunoglobulin was 54\% (27 of 50) for IgG and 4\% (2 of 50) for IgM. The prevalence of B19 viremia was $10 \%$ (5 out of 50 ) in HD subjects. One sample was found to be positive for both antibodies, while 5 cases (10\%) showed B19 IgG and viremia simultaneously. Anemia was present in $92 \%$ of the HD cases. In the present study, we did not observe a significant relation between the presence of B19 IgG, IgM and viremia and age, sex, mean duration of dialysis, and anemia.

In the PD group, $54.5 \%$ were male and $45.5 \%$ were female, and the mean duration of dialysis was $38.94 \pm 35.21$ months. The prevalence of B19 IgG and IgM was 57.6\% (19 of 33 ) and $0 \%$ respectively, whereas B19 DNA was found in $12.1 \%$ ( 4 of 33 ) of this group. Three cases (9.1\%) showed B19 IgG and viremia concurrently. Anemia was present in $78.8 \%$ of the PD patients. We did not find any significant relation between the presence of B19 IgG, IgM and viremia and age, sex, mean duration of dialysis, and anemia.

No significant difference between the PD and HD groups was found regarding B19 IgG, IgM, and viremia. Table 1 summarizes the ELISA and PCR results in the 2 groups. 


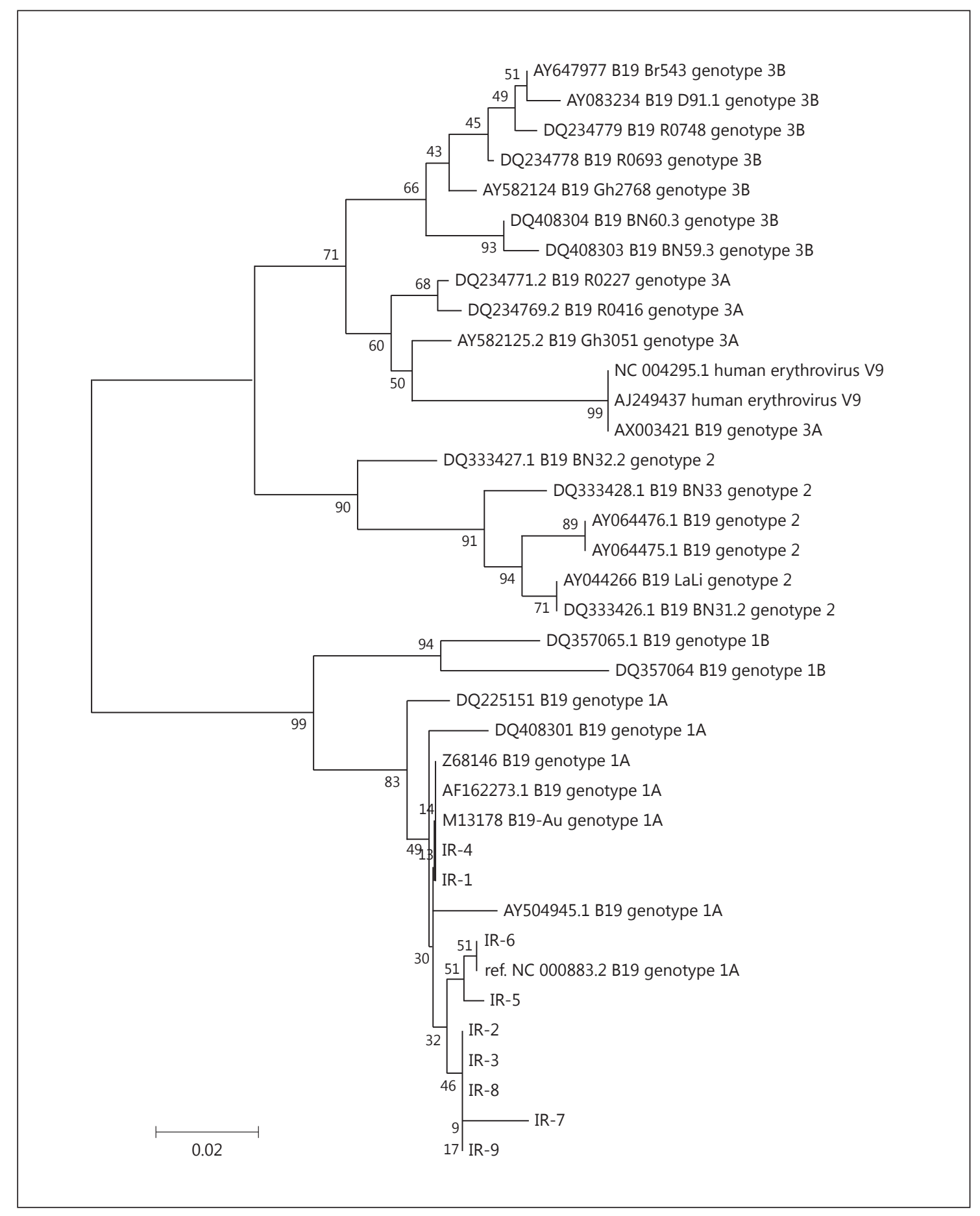

Fig. 1. Phylogenetic tree from the B19 VP2 region of 9 human parvovirus B19 strains isolated from Iranian HD and PD patients. Reference sequences for $1 \mathrm{~A}, 1 \mathrm{~B}, 2,3 \mathrm{~A}$, and 3B subtypes from the GenBank database were also included. The numbers next to the nodes of the tree represent bootstrap values (1,000 replicates). The Iranian sequences determined in this study are indicated by the IR prefix. IR-1 to 4 relate to PD patients and IR-5 to 9 were isolated from the HD group. 
Phylogenetic analysis revealed that all B19 isolates in the PD and HD groups clustered to genotype 1, and were classified as subtype B19-1A (Fig. 1). We also identified the nucleotide and amino acid divergence in our isolates. Comparing the nucleotide sequences revealed the overall variation to be 0.10879 (range $0.00-0.19990$ ). The mean intragenotypic nucleotide distance within Iranian isolates and other 1A isolates was 0.01167 (range 0.0000.03267 ). The mean variation between Iranian strains was 0.00848 and the maximum distance was 0.01924 .

By comparison of the amino acid sequences, the overall variation was 0.30818 (range $0.00-0.5877$ ). The mean intragenotypic amino acid distance within Iranian isolates and other 1A isolates was 0.03154 (range 0.0000.08894 ). The mean variation between Iranian strains was 0.02405 and the maximum distance was 0.06596 .

According to Figure 1 and the genetic distance analysis on isolates detected from the PD center, IR-1 and IR-4 were the same, while IR-2 and IR-3 had a similar genetic distance and fell in another branch of the phylogenetic tree. This suggests that 2 different B19 isolates are circulating in our PD center. Regarding isolates recovered from 1 HD center, IR- 8 and IR- 9 clustered in 1 branch of the phylogenetic tree, which may indicate that these isolates are similar, while IR-7 from the same dialysis center revealed some genetic distance $(0.02151)$ but was close to IR-8 and IR-9. Moreover, IR-5 and IR-6, which were obtained from another HD center, showed minimal genetic distance, demonstrating that they are only close to each other.

\section{Discussion}

This is the first report to investigate the serological and molecular characterization of parvovirus B19 in patients on HD and PD in Iran. The prevalence of B19specific immunoglobulin was $54 \%$ for IgG and $4 \%$ for $\operatorname{IgM}$, and $\mathrm{B} 19$ viremia was found in $10 \%$ of HD subjects, while $10 \%$ of HD cases showed B19 IgG and viremia simultaneously. In the PD group, the prevalence of B19 IgG and IgM was 57.6 and $0 \%$ respectively, whereas B19 DNA was found in $12.1 \%$. B19 IgG and viremia was concurrently shown in $9.1 \%$ of PD cases. Moreover, in the present study we did not observe a significant relation between the presence of B19 IgG, IgM, and viremia and anemia in both groups.

Anemia is common in patients with chronic kidney disease under dialysis [28] but the morbidity and mortality mainly depend on the etiology of anemia and the stage

Parvovirus B19 in Dialysis Patients of renal disease [29]. The significance of B19 infection in patients with chronic renal failure remains to be clarified. Patients undergoing dialysis may have increased susceptibility to acute and chronic anemia after B19 infection. The immunosuppression state in dialysis patients due to underlying diseases and immunosuppressive treatment may prevent an effective antiviral immune response relating to persistent viral infection and chronic suppression of erythropoiesis with the development of chronic anemia or B19-related recurrent anemia [30, 31]. Potentially life-threatening transient aplastic crisis due to B19 infection is also a major concern in some dialysis cases [11]. Finally, persistent B19 infection in patients on chronic dialysis can become clinically manifested after renal transplantation and the administration of immunosuppressive medications [13].

Previous investigations have described the B19 distribution in different settings and shown a variable epidemiological pattern among populations [32-35]. However, most surveys mainly focused on the prevalence of B19 in kidney transplant subjects, and few studies have been carried out on the B19 frequency in dialysis patients. In a study by Małyszko et al. [32], B19 IgM and IgG antibodies were detected in 16 and $49 \%$ of dialyzed patients, respectively. There were no significant differences among dialyzed patients with and without acute or chronic B19 infection regarding $\mathrm{Hb}$, erythrocyte count, and erythropoietin concentration.

In a study on 62 hemodialyzed patients, Guiserix et al. [36] reported that B19 infections play no role in leading chronic anemia in these subjects. Moreover, there was no correlation between time on dialysis and IgG antibodies.

Alves et al. [29] conducted a survey on 120 dialyzed patients (106 on HD and 14 on PD) and showed that the overall B19 seroprevalence was $67.5 \%$. There was no significant correlation between B19 infection and anemia. They suggested that B19 infection creates little problem in dialyzed patients.

We previously carried out a study on HIV patients and a control group [35]. The prevalence of B19 IgG, IgM, and DNA in the control group was $25,1.6$, and $9.4 \%$, respectively, while in the HIV group the prevalence of IgG, IgM, and B19 DNA was 11.1, 1, and 13.1\%, respectively. B19 IgG and viremia was simultaneously shown in $3 \%$ of HIV cases. In comparison with the present study, we reported a higher rate of IgG, IgM, and B19 DNA, and concurrent presence of IgG and viremia. Therefore, the prevalence of parvovirus B19 is very variable and the degree of immunodeficiency can explain the differences in the IgG seroprevalence and viremia found in different studies. It 
seems that dialysis patients have no problem in producing B19 antibodies in accordance with our results, while some studies have reported low rates of B19 IgG among HIV patients due to underlying immunological problems $[34,35]$. However, persistent B19 infection with coexisting IgG and viremia was found commonly in our HD cases, possibly due to a qualitative defect of antibodies for neutralizing the virus $[37,38]$. The clinical significance of B19 infection in patients undergoing dialysis is not clear, but persistent B19 viremia should be considered a potential risk through the contamination of dialysis equipment and subsequent threat to dialysis patients during transplantation procedures.

In agreement with other reports from most parts of the world, including Iran, genotype 1A was the only detectable genotype in this study group. In our survey, a low degree of nucleotide diversity among B19 strains was detected, which concurs with other reports $(<2 \%)$ [39]. However, in comparison to our previous study conducted in HIV patients and normal controls, we report a higher degree of nucleotide diversity in samples isolated from dialysis patients. Moreover, we have identified the same strains isolated from 1 dialysis center, revealing the possibility of nosocomial spread of B19 infection among dialysis patients. There are limited studies on this issue, al- though Ozeki et al. [3] described $1 \mathrm{HD}$ case with transient aplastic crisis due to nosocomial B19 infection.

In conclusion, this study investigated the serological and molecular characterization and importance of parvovirus B19 infection in patients under dialysis in Iran. Our findings indicate that B19 infection plays no role in leading chronic anemia in dialysis patients. However, persistent B19 viremia and the circulation of the same strains in dialysis patients may demonstrate a potential risk for the contamination of dialysis equipment and nosocomial spread of B19 infection within dialysis units. Further studies with larger samples are required to clarify the nosocomial spread of B19 infection in dialysis units as a potential threat, which could be clinically symptomatic after renal transplantation.

\section{Acknowledgements}

The authors are grateful to the Iranian Society for Support of Patients with Infectious Disease for financial support of this study.

\section{Disclosure Statement}

No conflicts of interest exist for any of the authors.

\section{References}

1 Corcoran A, Doyle S: Advances in the biology, diagnosis and host-pathogen interactions of parvovirus B19. J Med Microbiol 2004;53: 459-475.

2 Heegaard ED, Brown KE: Human parvovirus B19. Clin Microbiol Rev 2002;15:485-505.

3 Ozeki M, Fukushima T, Ohzeki M, Sasaki T, Kashihara N: A nosocomial parvovirus B19 infection-induced transient aplastic crisis in a patient with chronic renal failure. Clin Nephrol 2006;65:141-143.

4 Tanawattanacharoen S, Falk RJ, Jennette JC, Kopp JB: Parvovirus B19 DNA in kidney tissue of patients with focal segmental glomerulosclerosis. Am J Kidney Dis 2000;35:11661174.

5 Corcioli F, Zakrzewska K, Rinieri A, Fanci R, Innocenti M, Civinini R, De Giorgi V, Di Lollo S, Azzi A: Tissue persistence of parvovirus B19 genotypes in asymptomatic persons. J Med Virol 2008;80:2005-2011.

6 Schenk T, Enders M, Pollak S, Hahn R, Huzly D: High prevalence of humanparvovirus B19 DNA in myocardial autopsy samples from subjects without myocarditis or dilative car- diomyopathy. J Clin Microbiol 2009;47:106110.

7 Plentz A, Würdinger M, Kudlich M, Modrow S: Low-level DNAemia of parvovirus B19 (genotypes 1-3) in adult transplant recipients is not associated with anaemia. J Clin Virol 2013;58:443-448.

8 Henriques I, Monteiro F, Meireles E, Cruz A, Tavares G, Ferreira M, Araújo F: Prevalence of parvovirus B19 and hepatitis A virus in Portuguese blood donors. Transfus Apher Sci 2005;33:305-309.

9 Tolkoff-Rubin N, Rubin R: Uremia and host defenses. N Engl J Med 1990;322:770-772.

10 Vanholder R, Loo V, Dhondt AM, Smet RD, Ringoir S: Influence of uraemia and haemodialysis on host defense and infection. Nephrol Dial Transplant 1996;11:593-598.

11 Duranay M, Bali M, Sahin M, Yakinci G, Vurgun N, Dilmen U: Parvovirus B19 infection and unresponsiveness to erythropoietin therapy in haemodialysis patients. Nephrol Dial Transplant 1998;13:779-780.

12 Arzouk N, Snanoudj R, Beauchamp-Nicoud A, Mourad G, Charpentier B, Tchernia G,
Durrbach A: Parvovirus B19-induced anemia in renal transplantation: a role for $\mathrm{rHuEPO}$ in resistance to classical treatment. Transpl Int 2006; 19:166-169.

13 Waldman M, Kopp JB: Parvovirus B19 and the kidney. Clin J Am Soc Nephrol 2007; 2(suppl 1):S47-S56.

14 Söderlund-Venermo M, Hokynar K, Nieminen J, Rautakorpi H, Hedman K: Persistence of human parvovirus B19 in human tissues. Pathol Biol (Paris) 2002;50:307-316.

15 Adamson-Small LA, Ignatovich IV, Laemmerhirt MG, Hobbs JA: Persistent parvovirus B19 infection in non-erythroid tissues: possible role in the inflammatory and disease process. Virus Res 2014;190:8-16.

16 Kerr JR: A review of blood diseases and cytopenias associated with human parvovirus B19 infection. Rev Med Virol 2015;25:224-240.

17 Aghakhani A, Mohraz M, Azadmanesh K, Moayedi-Nia S, Kazemimanesh M, Mamishi S, Banifazl M, Ramezani A: No evidence of persistent parvovirus B19 viremia among Iranian patients with HIV after a 1-year followup. Arch Virol 2016;161:1183-1187. 
18 Nowalany-Kozielska E, Kozieł M, DomalKwiatkowska D, Wojciechowska C, Jacheć W, Kawecki D, Tomasik A, Przywara-Chowaniec B, Węglarz L, Reichman-WarmuszE, Wojnicz $\mathrm{R}$ : Clinical significance of viral genome persistence in the myocardium of patients with dilated cardiomyopathy. Intervirology 2015; 58:350-356.

19 Servant A, Laperche S, Lallemand F, Marinho V, de SaintMaur G, Meritet JF, Garbarg-Chenon A: Genetic diversity within human erythroviruses identification of three genotypes. J Virol 2002;76:9124-9134.

20 Pereira RFA, Cubel Garcia RCN, Azevedo KLM, Setúbal S, Siqueira MAMT, Castro TX, Oliveira SA: Molecular characterization of human parvovirus B19 strains circulating in Niterói/RJ - Brazil. Virus Rev Res 2012; 17(suppl):158-159.

21 Liefeldt L, Plentz A, Klempa B, Kershaw O, Endres AS, Raab U, Neumayer HH, Meisel H, Modrow S: Recurrent high level parvovirus B19/genotype 2 viremia in a renal transplant recipient analyzed by real-time PCR for simultaneous detection of genotypes 1-3. J Med Virol 2005;75:161-169.

22 Hokynar K, Söderlund-Venermo M, Pesonen M, Ranki A, Kiviluoto O, Partio EK, Hedman $\mathrm{K}$ : A new parvovirus genotype persistent in human skin. Virology 2002;302:224-228.

23 Nguyen QT, Wong S, Heegaard ED, Brown KE: Identification and characterization of a second novel human erythrovirus variant, A6. Virology 2002;301:374-380.

24 Sanabani S, Neto WK, Pereira J, Sabino EC: Sequence variability of human erythroviruses present in bone marrow of Brazilian patients with various parvovirus B19-related hematological symptoms. J Clin Microbiol 2006;44: 604-606.
25 Candotti D, Etiz N, Parsyan A, Allain JP: Identification and characterization of persistent human erythrovirus infection in blood donor samples. J Virol 2004;78:12169-12178.

26 World Health Organization: WHO Essential Medicines Library - EMLib: Iron Deficiency Anemia. Geneva, WHO, 2004.

27 Melon S, Deona M, Grande JA, Laures AS, Gomez Hurtas E: Infección por parvovirus B19 en trasplante renal. Diagnóstico por detección del genoma viral en sangre periférica. Nefrologia 2005;25:67-72.

28 Kazmi WH, Kausz AT, Khan S, Abichandani R, Ruthazer R, Obrador GT, Pereira BJ: Anemia: an early complication of chronic renal insufficiency. Am J Kidney Dis 2001;38:803812.

29 Alves MT, Vilaça SS, Godoi LC, Rezende Júnior L, Carvalho Md, Silva Fde S, Guimarães FL, Fernandes AP, Dusse LM, Gomes KB: Parvovirus B19 (B19) and cytomegalovirus $(\mathrm{CMV})$ infections and anti-erythropoietin (anti-EPO) antibodies in patients on dialysis hyporesponsive to erythropoietin therapy. Clin Chim Acta 2014;431:52-57.

30 Rerolle JP, Morelop E, Hetal I, Peraldi MN, Mamzer-Bruneel MF, Kreis H: Parvovirus B19-related anemia after renal transplantation. Scand J Infect Dis 2004;36:513-516.

31 Kumar J, Shaver MJ, Abul-Ezz S: Long-term remission of recurrent parvovirus B19-associated anemia in a renal transplant recipient induces by treatment with immunoglobulin and positive seroconversion. Transpl Infect Dis 2005; 7:30-33.

32 Małyszko J, Hryszko T, Małyszko JS, Wolczyński S, Myśliwiec M: Parvovirus B19 infection and IGF system components in relation to erythropoiesis in dialyzed patients and kidney transplant recipients. Transplant Proc 2002;34:3211-3214.
33 He M, Zhu J, Yin H, Ke L, Gao L, Pan Z, Yang X, Li W: Human immunodeficiency virus/human parvovirus $\mathrm{B} 19$ co-infection in blood donors and AIDS patients in Sichuan, China. Blood Transfus 2012;10:502-514.

34 Lee YM, Chuang SY, Wang SF, Lin YT, Chen YM: Epidemiology of human herpesvirus type 8 and parvovirus B19 infections and their association with HIV-1 among men who have sex with men and injection drug users in Taiwan. J Microbiol Immunol Infect 2014;47: 233-238.

35 Azadmanesh K, Mohraz M, Kazemimanesh M, Aghakhani A, Foroughi M, Banifazl M, Eslamifar A, Ramezani A: Frequency and genotype of human parvovirus B19 among Iranian patients infected with HIV. J Med Virol 2015;87:1124-1129.

36 Guiserix J, Ramdane M, Hoarau JM, Finielz P, Michault A: Parvovirus B19 and hemodialysis. Nephron 1996;72:719.

37 Frickhofen N, Abkowitz JL, Safford M, Berry JM, Antunez-de-Mayolo J, Astrow A, Cohen R, Halperin I, King L, Mintzer D, Cohen B, Young NS: Persistent B19 parvovirus infection in patients infected with human immunodeficiency virus type 1 (HIV-1): a treatable cause of anemia in AIDS. Ann Intern Med 1990;113:926-933.

38 Chernak E, Dubin G, Henry D, Naides SJ, Hodinka RL, MacGregor RR, Friedman HM: Infection due to parvovirus B19 in patients infected with human immunodeficiency virus. Clin Infect Dis 1999;20:170-173.

39 Erdman DD, Durigon EL, Wang QY, Anderson LJ: Genetic diversity of human parvovirus B19: sequence analysis of the VP1/VP2 gene from multiple isolates. J Gen Virol 1996;77: $2767-2774$ 